\title{
Biosynthesis and characterization of silver nanoparticles using Trichoderma longibrachiatum and their effect on phytopathogenic fungi
}

\author{
Rabab M. Elamawi ${ }^{i^{*}}$, Raida E. Al-Harbi² and Awatif A. Hendi ${ }^{3}$
}

\begin{abstract}
An efficient biosynthesis process for the rapid production of nanoparticles would enable the development of a "microbial nanotechnology" for mass-scale production. In the present research, biological silver nanoparticle was synthesized extracellularly by using the fungus, Trichoderma longibrachiatum, where the cell filtrate of the fungus was used as a reducing and stabilizing agent in the process of nanoparticle synthesis. Different physical parameters such as fungal biomass concentration $(1,5,10,15$, and $20 \mathrm{~g})$, temperature $\left(25,28\right.$, and $\left.33^{\circ} \mathrm{C}\right)$, incubation time $(0-120 \mathrm{~h})$ , and agitation (shaken or not shaken) were investigated, in order to determine the optimal conditions for nanoparticle biosynthesis. The stability and antifungal properties of the synthesized silver nanoparticles (AgNPs) were also determined. Data revealed that a combination of $10 \mathrm{~g}$ fungal biomass, a reaction temperature of $28^{\circ} \mathrm{C}$, a 72 -h incubation time, and without shaking were the optimum conditions for the synthesis of the silver nanoparticles. Visual observation of brown color is an indication of silver nanoparticle production. UV-vis spectroscopy showed maximum absorption at $385 \mathrm{~nm}$ with the optimum conditions. Transmission electron microscopy (TEM) revealed the formation of monodispersed spherical shape with a mean diameter of $10 \mathrm{~nm}$. Fourier transformation infrared (FTIR) showed bands at1634.92 and 3269. $31 \mathrm{~cm}^{-1}$. Dynamic light scattering (DLS) supported that the Z-average size was 24.43 and $0.420 \mathrm{Pdl}$ value. Zeta potential showed $-19.7 \mathrm{mV}$ with a single peak. The AgNPs synthesized through this biosystem approach were relatively stable up to 2 months after synthesis. The use of AgNPs as antifungal led to significant reductions in the number of forming colonies for many plant pathogenic fungi, with efficiencies reaching up to $90 \%$ against Fusarium verticillioides, Fusarium moniliforme, Penicillium brevicompactum, Helminthosporium oryzae, and Pyricularia grisea. However, further research should be carried out in order to determine the toxic effect of AgNPs before mass production and use of agricultural applications.
\end{abstract}

Keywords: Trichoderma longibrachiatum, Silver nanoparticles, UV-vis spectroscopy, TEM, FTIR, DLS, Zeta potential, Antifungal activity

\section{Background}

Silver nanoparticles are widely used in many applications in various fields such as bio-labeling, sensors, antimicrobial agents, filters, microelectronics, and catalysis. This is because of their specific physico-chemical and biological properties (Pal et al. 2007; Ingle et al. 2008; Kim et al. 2008; Rai et al. 2009). Silver nanoparticles (AgNPs) have

\footnotetext{
*Correspondence: rabab.elamawi@yahoo.com

'Rice Pathology Department, Plant Pathology Research Institute, Agricultural Research Center, PO Box 33717, Sakha, Kafr Elshiekh, Egypt

Full list of author information is available at the end of the article
}

inhibitory effects on the growth of bacteria, virus, and other eukaryotic microorganisms (Jeong et al. 2005). In addition to their distinctive properties, their production cost is relatively low (Capek 2004). Physical and chemical methods have been utilized for the synthesis of nanoparticles (Mandal et al. 2005; Solanki and Murthy 2010; Huang et al. 2011). Basically, the physical methods have affected low yields, while the chemical ones caused harmful effects on the environment due to use of toxic solvents and the regeneration of hazardous by-products (Wang et al. 2007). Biosynthetic methods have been investigated as an 
alternative to chemical and physical methods. Microorganisms have been explored as potential bio-factories for synthesis of metallic nanoparticles such as cadmium sulphide, gold, and silver (Sastry et al. 2003). Biosynthesized nanoparticles are eco-friendly, reliable, biocompatible, and low cost (Roy et al. 2013; Emeka et al. 2014).

Silver nanoparticles may be less toxic to humans and animals than synthetic fungicides. Moreover, the toxicity that nanoparticles may cause in algae, plants, and fungi may be coupled with some positive effects (Sondi and Salopek-Sondi 2004). Recent studies in mammals and human cells have demonstrated that AgNPs are cytotoxic to various types of cells (Vandebriel et al. 2014; AshaRani et al. 2009). Other studies have shown that AgNPs accumulate in various types of cells (blood, liver, lungs, kidneys, stomach, testes, and brain) but showed no significant genotoxicity function (Kim et al. 2008). AgNPs effectively inhibit microorganisms without causing significant cytotoxicity also; AgNPs are nontoxic in mice and guinea pigs when administered by oral, ocular, and dermal routes. These conflicting results reveal the difficulty of pinpointing the overall toxicity of AgNPs to humans because the tremendous variation in particle size, particle aggregation, and concentration or coating thickness (in implants) of AgNPs has different profiles of silver release and bioactivity. In short, much longer and detailed studies have to be carried out to seriously consider AgNPs' potential toxicity in humans (Sharma et al. 2009; Murphy et al. 2015).

Biologically synthesized AgNPs could have many applications (Schultz et al. 2000; Durán et al. 2005). Different genera of fungi have been reported to synthesize metal nanoparticles (Ahmad et al. 2003; Mukherjee et al. 2002; Sastry et al. 2003; Mandal et al. 2005).

The fungal genus Trichoderma (Ascomycetes, Hyprocreales) contains species that are of vast economic importance owing to their production of industrial enzymes and antibiotics (Sivasithamparam and Ghisalberti 1998) and their ability to act as biological control agents against plant pathogens. In the biosynthesis of metal nanoparticles by a fungus, its mycelium is exposed to the metal salt solution, which prompts the fungus to produce enzymes and metabolites for its own survival. In this process, the metal ions are reduced to the metallic solid nanoparticles through the catalytic effect of the extracellular enzyme and metabolites of the fungus (Das and Marsili 2010; Vahabi et al. 2011).

The objectives of the present work were to determine the optimal conditions for the synthesis of biogenic silver nanoparticles, using a filtrate of the fungus $T$. longibrachiatum and its characterization, and also the stability and antimicrobial activity of the synthesized AgNPs against phytopathogenic fungi.

\section{Materials and methods}

\section{Isolation and identification of fungal isolates}

Fungal isolates were collected from cucumber, tomato, and pepper plants from around Alryadah city, Saudi Arabia, during 2013 and purified, using hyphal tip standard techniques, and maintained on a potato dextrose agar (PDA) slant and stored at $4{ }^{\circ} \mathrm{C}$ until further use. Fungal isolates were identified as $T$. longibrachiatum (cucumber), T. viride (cucumber), T. harzianum (tomato), F. verticillioides (pepper), Alternaria alternate (tomato), and Rhizopus stolonifer (pepper) based on the publication by Barnett and Hunter (1995). Further identification was done by Nano Technology Center for Scientific Services in Egypt, using fingerprint biotechnology according to Harman et al. (2004) and Harman (2006). Three Trichoderma species viz. T. longibrachiatum, T. viride, and $T$. harzianum were screened for their ability to synthesize silver nanoparticles. The isolates were cultured in PDA and incubated at $25{ }^{\circ} \mathrm{C}$ for 5 days and used for extracellular syntheses of silver nanoparticles. The fungal isolates; $F$. moniliforme, A. flavus, $P$. grisea, and $H$. oryzae were obtained from Rice Pathology Department, Sakha, Kafr Elshiekh.

\section{Fungal biomass preparation for AgNP biosynthesis}

Two disks ( $5 \mathrm{~mm}$ in diameter) of each fungus were inoculated onto $100 \mathrm{ml}$ of liquid medium containing $(\mathrm{g} / \mathrm{l})$ $\mathrm{KH}_{2} \mathrm{PO}_{4} 7.0, \mathrm{~K}_{2} \mathrm{HPO}_{4} 2.0, \mathrm{MgSO}_{4} 7 \mathrm{H}_{2} \mathrm{O} 0.1,\left(\mathrm{NH}_{4}\right)_{2} \mathrm{SO} 4$ 1.0 , yeast extract 0.6 , and glucose 10 . The flasks were incubated in a shaker at $150 \mathrm{rpm}$ at $25-28{ }^{\circ} \mathrm{C}$. After $120 \mathrm{~h}$ of growth, the pale white fungal mycelium took the shape of a circular mat (Fig. 1a). Then, the biomass was harvested by sieving through a Whatman filter paper no.1, followed by extensive washing with Milli-Q deionized water to remove any adhering medium parts from the biomass.

\section{Optimization conditions for biosynthesis of silver nanoparticles}

The effect of fungal biomass $(5,1,10,15$, and $20 \mathrm{~g})$, temperature $\left(23,28\right.$, and $\left.33{ }^{\circ} \mathrm{C}\right)$, and agitation on constant shaking at $150 \mathrm{rpm}$ or without agitation were studied by varying one parameter at a time, keeping the other experimental conditions the same.

\section{Biosynthesis of silver nanoparticles}

Experiments were conducted with the fungal biomass and with a liquid medium in parallel. The fungal biomass was brought into contact with $100 \mathrm{ml}$ Milli-Q deionized water for $48 \mathrm{~h}$ at $28{ }^{\circ} \mathrm{C}$ at $150 \mathrm{rpm}$. After filtration by Whatman filter paper no.1, $50 \mathrm{ml}$ of $1 \mathrm{mM}$ $\mathrm{AgNO}_{3}$ solution was mixed with $50 \mathrm{ml}$ of cell filtrate in a $250 \mathrm{ml}$ Erlenmeyer flask, kept on a shaker at $150 \mathrm{rpm}$ 


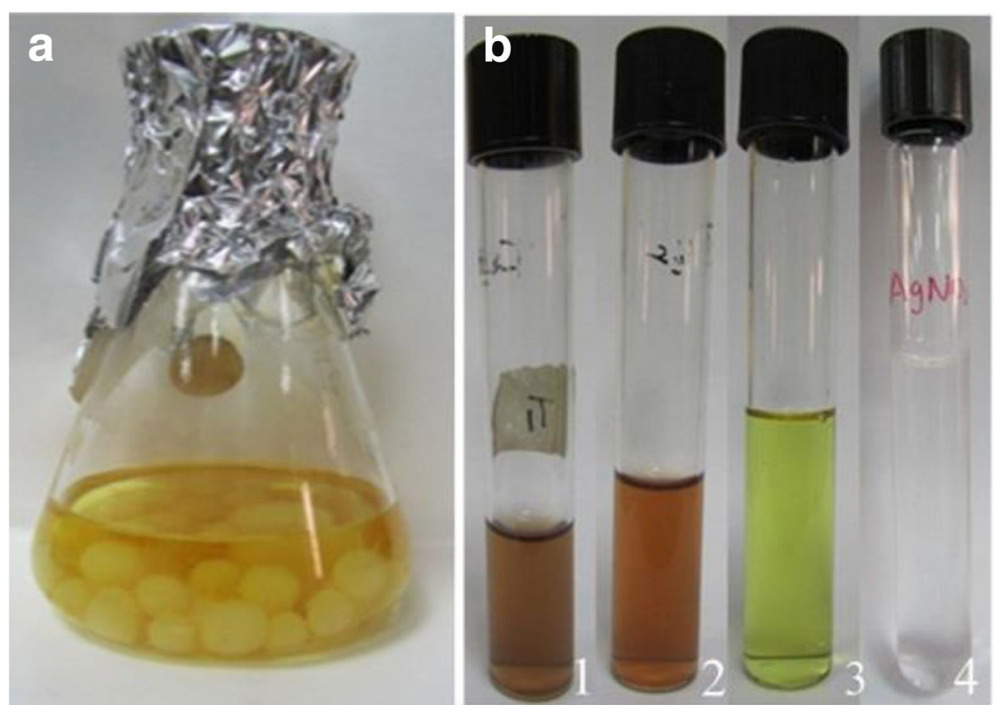

Fig. 1 Culture matt of fungus Trichoderma longibrachiatum in liquid media (a). b Biosynthesis of silver nanoparticle color change reaction after exposure to $\mathrm{AgNO}_{3}$ solution for $96 \mathrm{~h}$ : (1) T. viride, (2) T. harzianum, (3) T. longibrachiatum, (4) $\mathrm{AgNO}_{3} 1 \mathrm{mM}$ solution

or without shaking at 23,28 , and $33{ }^{\circ} \mathrm{C}$ in the dark. The positive control is the only fungal biomass filtrate without the silver nitrate solution, and the negative control is the silver nitrate solution without cell-free filtrate. The reduction of metal ions was routinely monitored by visual inspection of the solution (color change from yellow to brown) and by measuring the ultraviolet-visible spectrophotometer of the solution by periodic sampling of aliquots $(1 \mathrm{ml})$ of the aqueous component. The formed silver nanoparticles were subjected to different instrumental analytical techniques for characterization.

\section{Characterization of silver nanoparticles Ultraviolet-visible spectrophotometer analysis}

The formation of the reduced silver nanoparticles in colloidal solution was monitored by using a UV-vis spectrophotometer (Lambda 25, PerkinElmer, precisely, UK). The absorption spectra of the supernatants were taken between 300 and $700 \mathrm{~nm}$, using a UV-vis spectrophotometer. The deionized water was used as the blank.

\section{Fourier transform infrared (FTIR) spectroscopy}

The FTIR spectrum of biosynthesized silver product was recorded on a FTIR instrument mode Nicolet 6700 spectrometer at a resolution of $4 \mathrm{~cm}^{-1}$ attachment. All measurements were carried out in the range of $400-4000 \mathrm{~cm}^{-1}$ at a resolution of $4 \mathrm{~cm}^{-1}$.

\section{Transmission electron microscopy (TEM)}

TEM was performed on JEOL, Japan (JEM-1010) instrument, within accelerating voltage of $80 \mathrm{kV}$ after drying of a drop of aqueous AgNPs on the carbon coated copper. TEM grid samples were dried and kept under vacuum in desiccators before loading on a specimen holder. The particle size distribution of AgNPs was evaluated using ImageJ $1.45 \mathrm{~s}$ software1493.

\section{Dynamic light scattering}

Zetasizer Nano ZS, Malvern Instruments Ltd., UK, was used to determine the size distribution of particles by measuring dynamic fluctuations of light scattering intensity caused by the Brownian motion of the particles. The measurement gave the average hydrodynamic diameter of the particles, the peak values in the hydrodynamic diameter distribution, and the polydispersity index (PdI) that described the width of particle size distribution. The PdI scale ranges from 0 to 1 (with 0 being monodisperse and 1 being polydisperse). All measurements were carried out in triplicate with a temperature equilibration time of $1 \mathrm{~min}$ at $25{ }^{\circ} \mathrm{C}$. The data processing mode was set to high multi-modal resolution. The suspension of the synthesized silver nanoparticles was diluted $(20,40$, 60,80 , and $100 \%$ ), and the diluted sample was allowed to filter through a $0.22-\mu \mathrm{m}$ syringe driven filter unit or without filtration.

\section{Antifungal activity for AgNPs synthesized in in vitro assays} The antifungal activity of nanoparticles was examined on the basis of colony formation technique by in vitro Petri dish (Elamawi and El-Shafey 2013). The antifungal activity of the synthesized AgNPs was examined against the pathogenic fungi: A. alternate, $F$. oxysporum, $F$. verticillioides, $F$. moniliforme, Aspergillus flavus, A. heteromorphus, P. glabrum, $P$. brevicompactum, $P$. grisea, and $H$. oryzae. Fungal 
spores at a concentration of $10^{5}$ spores $/ \mathrm{ml}$ were incubated at $0.5 \mathrm{mM} \mathrm{AgNP}$ solution, $1 \mathrm{mM} \mathrm{AgNO}_{3}$ solution, and sterile, distilled water as a control at $28{ }^{\circ} \mathrm{C}$ for $24 \mathrm{~h}$ in a shaker $(120 \mathrm{rpm})$. A $25-\mu \mathrm{l}$ aliquot of the spore suspension was spread on PDA. Three PDA plates per combination were used as replicates. The number of formed colonies was counted after 24 and $48 \mathrm{~h}$. The average numbers of colonies from silver-treated spore suspensions were compared to the number of colonies of $\mathrm{AgNO}_{3}$ solution and with the control (water treatment).

\section{Statistical analysis}

The null hypothesis may be rejected, and there is a $95 \%$ confidence level that the parameters are not the same as were tested, using one-way analysis of variance (ANOVA), followed by LSD post hoc test, when significant differences were found $(P \leq 0.05)$. Statistical significance of results obtained from treating fungi with both Ag-NPs and $\mathrm{AgNO}_{3}$ were compared to control.

\section{Results and discussion}

\section{Characterization of AgNPs}

Three Trichoderma species viz. T. longibrachiatum, $T$. viride, and T. harzianum were used for biosynthesis of stable AgNPs. Filtrates of each fungal isolates were incubated with $\mathrm{AgNO}_{3}$ and maintained with agitation under dark conditions at $28{ }^{\circ} \mathrm{C}$. Color change from pale yellow to brown appeared after the incubation period of $72 \mathrm{~h}$ with the T. harzianum and T. viride, but there was no color change with T. longibrachiatum (Fig. 1b). The appearance of the brown color was an indication of the formation of AgNPs in the medium. The positive control (without the $\mathrm{AgNO}_{3}$ solution, only fungal biomass) and the negative control (pure $\mathrm{AgNO}_{3}$ solution without cell-free filtrate) did not show any change of color for the mixture reaction (Fig. 1b). The above conditions were recommended for the production of silver nanoparticles from T. harzianum and T. viride. However, it could not be recommended to produce silver nanoparticles from $T$. longibrachiatum. So, optimization of some factors affecting silver production from T. longibrachiatum is required.

UV-visible spectrum of the biosynthesis of silver nanoparticles using the fungi of $T$. harzianum and $T$. viride showed a peak at 420 and $420 \mathrm{~nm}$ corresponding to the plasmon absorbance of silver nanoparticles for the tested fungi $T$. harzianum and T. viride, respectively. Particle size analysis using TEM of AgNPsof $T$. harzianum and $T$. viride showed a formation of polydispersed AgNPs in a range of 30-50 nm with $T$. harzianum and 5-40 $\mathrm{nm}$ with $T$. viridi, as reported by Fayaz et al. (2010) and Singh and Balaji (2011).

\section{Optimization conditions for biosynthesis of silver} nanoparticles

Effect of quantity of fungal biomass and agitation

Five different quantities of fungal biomass of $T$. longibrachiatum $(1,5,10,15$, and $20 \mathrm{~g})$ were subjected to $1 \mathrm{mM} \mathrm{AgNO}_{3}$ solution, incubated at $28{ }^{\circ} \mathrm{C}$, with or without agitation. The mixture reaction showed a change in color from light yellow to dark brown after $72 \mathrm{~h}$ of incubation without shaking with the amounts of 5, 10, 15, and $20 \mathrm{~g}$ fungal biomass (Fig. 2).

The UV-visible absorption spectroscopy of $T$. longibrachiatum was measured by the fungal biomass 10,15 , and $20 \mathrm{~g}$ at different times (72, 96, and $120 \mathrm{~h}$ ) of reaction time as presented in Fig. 3. It was observed that the formation of AgNPs increases with the increase of the quantity of fungal biomass. The time of reaction started at $72 \mathrm{~h}$ and maximized at $120 \mathrm{~h}$ without significant differences between quantities of fungal biomass. The range of absorbance was at $384 \mathrm{~nm}$. This event clearly indicated that the reduction of the ions occurs extracellularly through reducing agents released into the solution by $T$. longibrachiatum. The control treatment without silver ions showed no change in color, when incubated under the same conditions. The color changes observed could be attributed to the surface plasmon resonance of deposited AgNPs. The increase in color intensity of culture filtrate was due to an increase in number of nanoparticles formed from the reduction of silver ions present in the aqueous solution. The amount of fungal biomass was a key parameter that affects the process of AgNP synthesis from $T$. longibrachiatum.

\section{Effect of temperature}

Three temperatures 23,28 , and $33{ }^{\circ} \mathrm{C}$ with five quantities of fungal biomass, without agitation, in the presence of $1 \mathrm{mM} \mathrm{AgNo}$, were tested. The temperature of $28{ }^{\circ} \mathrm{C}$ was favorable for the production of AgNPs by T. longibrachiatum where color changed after $72 \mathrm{~h}$ of incubation with $\mathrm{AgNO}_{3}$. The UV-visible absorption spectroscopy of the $T$. longibrachiatum incubated at $28{ }^{\circ} \mathrm{C}$ showed a maximum absorbance at $385 \mathrm{~nm}$. Incubation at 23 and $33{ }^{\circ} \mathrm{C}$ showed no change in color when incubated under the same conditions. Reaction temperature had an important effecton enzyme activity. Fayaz et al. (2009) found that the size of biosynthesized silver nanoparticles by $\mathrm{T}$. viride ranged from 10 to 40 $\mathrm{nm}$ at $27^{\circ} \mathrm{C}$. While, at a lower temperature $\left(10{ }^{\circ} \mathrm{C}\right)$, the size of silver nanoparticles ranged from 80 to $100 \mathrm{~nm}$. Thus, these findings are different from those which showed that an increase in reaction temperature resulted in a decrease in particle size, whereas a decrease 


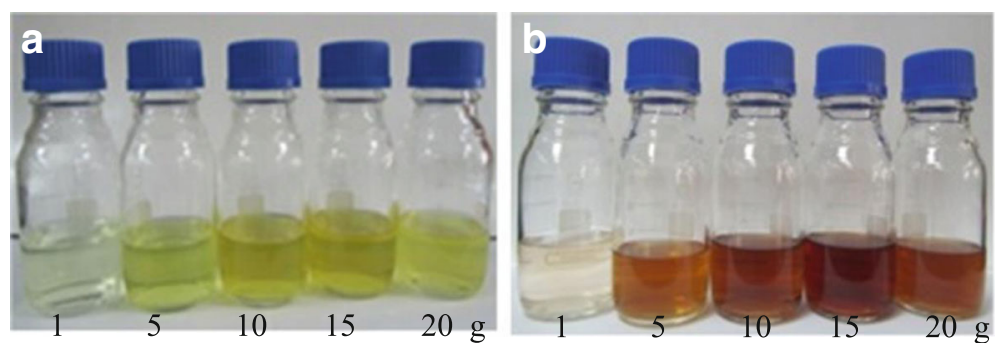

Fig. 2 Color change observed in cell-free fungal extract of Trichoderma longibrachiatum biomass after exposure to $\mathrm{AgNO}_{3}$ ions at $28{ }^{\circ} \mathrm{C}$ with $\mathbf{a}$ agitation or $\mathbf{b}$ without agitation

in temperature resulted in an increase in particle size. This could be explained that $28{ }^{\circ} \mathrm{C}$ was favorable for biosynthesis of AgNPs by T. longibrachiatum, while 23 and $33{ }^{\circ} \mathrm{C}$ were unfavorable.

There is a relation between the particle size and the plasmon peak, as the particles became larger when the plasmon peak shifts to longer wavelengths. Values for Ag particle size and plasmon maxima that were reported with Solomon et al. (2007) indicated that UV spectra were in lower wavelengths (384-414), with 10- to 14-nm particle size. Nair and Pradeep (2003) revealed that UV spectra at $438 \mathrm{~nm}$ wavelength gave particle sizes of $60-80 \mathrm{~nm}$. Obtained results indicated that lower wavelengths of UV spectra at $383 \mathrm{~nm}$ recorded particle sizes at 1-25 nm at $28{ }^{\circ} \mathrm{C}$.

\section{Effect of filtration}

The effect of filtration on the AgNPs, produced from 10 or $15 \mathrm{~g}$ fungal biomass of $T$. longibrachiatum, using UV-vis spectrophotometer was illustrated in Fig. 4. The plasmon peak shifted to longer wavelengths $(414 \mathrm{~nm})$ with a fungal biomass of $10 \mathrm{~g}$. No significant differences between non-filtered and filtered samples were observed with $15 \mathrm{~g}$ of fungal biomass, as the plasmon peak obtained by UV-vis spectrophotometer was $385 \mathrm{~nm}$.
Parametric optimization studies revealed that fungal biomass of 10 or $15 \mathrm{~g}$ at $28{ }^{\circ} \mathrm{C}$, without shaking or filtration, is favorable for the production of AgNPs by T. longibrachiatum. There was always a continuous interaction between the organisms and the environment they lived in.

\section{FTIR spectroscopy analysis}

The FTIR spectroscopy is very important to characterize the proteins binding with the AgNPs, and it is possible to quantify secondary structure in metal nanoparticle-protein interaction. FTIR spectroscopy was carried out on AgNPs synthesized with both 10 and $15 \mathrm{~g}$ fungal biomass formed after $96 \mathrm{~h}$ of incubation with $\mathrm{AgNO}_{3}$. As shown in Fig. 5, FTIR spectrum revealed bands at $1634.92,2156.94$, and $3269.31 \mathrm{~cm}^{-1}$. A band at $1634.92 \mathrm{~cm}^{-1}$ corresponded to the bending vibrations of the amide I and amide II bands of proteins (Gole et al. 2001), while their corresponding stretching vibrations of primary amines were observed at $3269.31 \mathrm{~cm}^{-1}$. Similar FTIR spectrums were obtained with 10 or $15 \mathrm{~g}$ final biomass (Fig. 5). These observations indicated the presence and binding of proteins with AgNPs, which can lead to their possible stabilization and prevent agglomeration. FTIR results revealed that secondary structure of proteins had not been affected as a consequence of reaction with silver ions or binding with AgNPs (Jain et al. 2011). FTIR

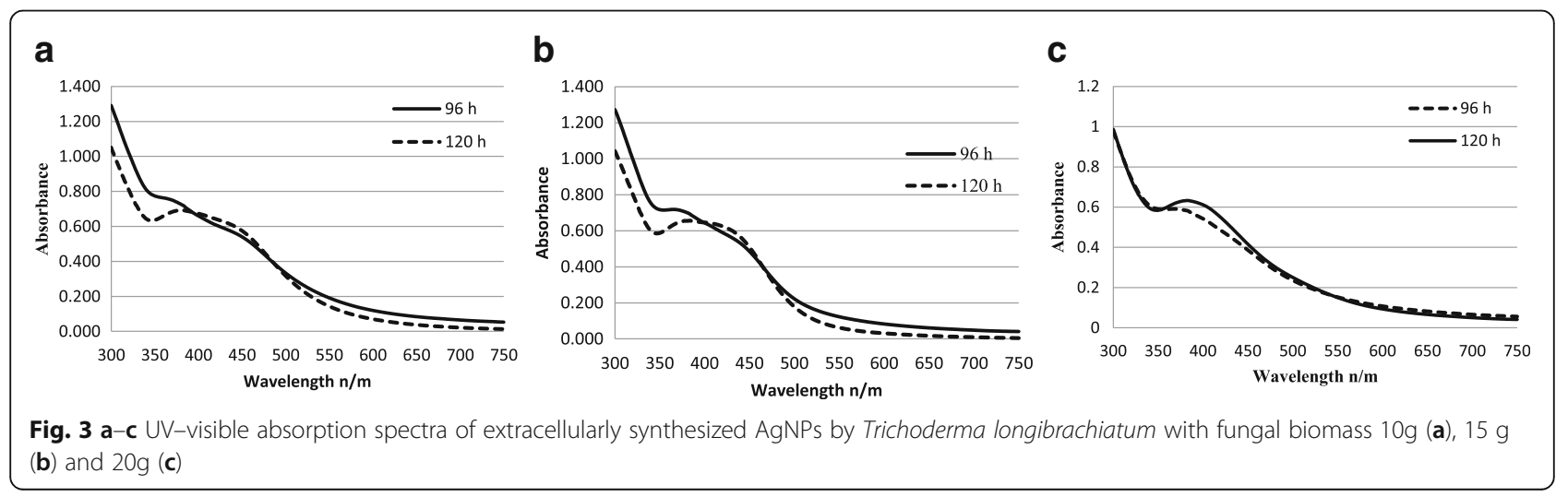



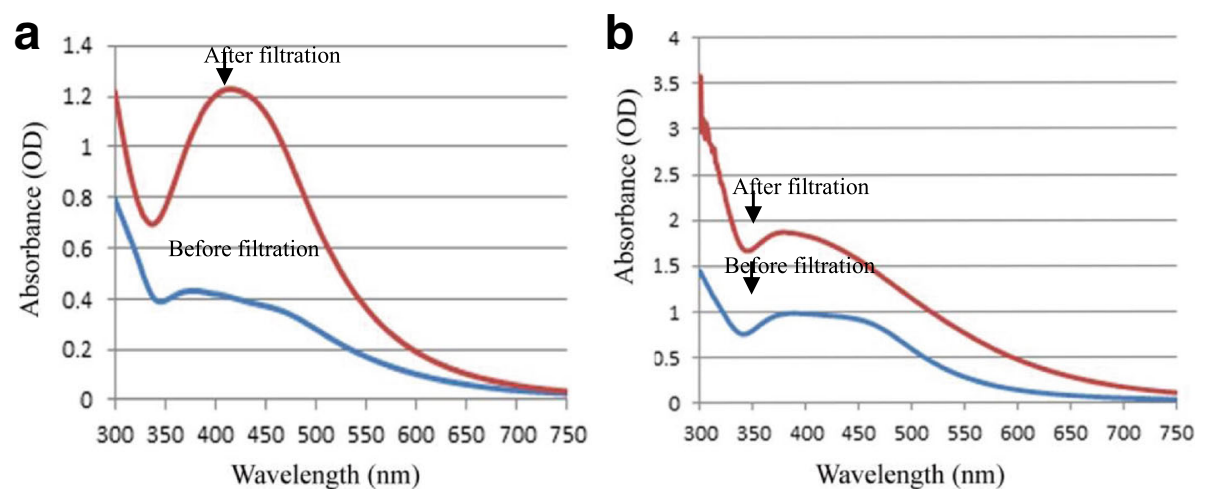

Fig. 4 UV-visible absorption spectrum of synthesized AgNPs by Trichoderma longibrachiatum for a $10 \mathrm{~g}$ biomass and $\mathbf{b} 15 \mathrm{~g}$ biomass, before and after filtration with filter size $0.22 \mu \mathrm{m}$

spectroscopic study confirmed that amino acid and peptides form a coat covering the silver nanoparticles. The presence of the signature peaks of amino acids supports the presence of proteins in cell-free filtrate as observed in UV-vis spectra. It is well known that nanoparticle-protein interactions can occur either through free amino groups or cysteine residues in proteins and via the electrostatic attraction of negatively charged carboxylate groups in enzyme proteins (Gole et al. 2001 and Mandal et al. 2005). The carbonyl groups of amino acid residues and peptides had strong ability to bind to silver (Balaji et al. 2009). The proteins present over the silver nanoparticle surface act as capping agents. These results agreed with the results obtained with $A$. niger (Jaidev and Narasimha 2010).

\section{Transmission electron microscope}

TEM images were taken for AgNPs of two fungal biomasses (10 and $15 \mathrm{~g}$ ) before and after filtration. TEM micrograph images showed monodispersed roughly spherical shapes with variable sizes. The particle size distribution of the AgNPs (Fig. 6) showed an average count of 500 AgNPs with sizes ranging from 1 to $25 \mathrm{~nm}$. AgNPs with sizes $\geq 5 \mathrm{~nm}$ accounted for $45.4 \%$ of particles, while those with sizes of $\geq 10$ and $\geq 15 \mathrm{~nm}$ accounted 24.8 and $16 \%$, respectively (Fig. 7). TEM micrographs taken before filtration showed aggregates and debris in both fungal biomass of 10 and $15 \mathrm{~g}$. After the filtration, the TEM micrograph appeared clear and the AgNPs were sphericalshaped and monodispersed with sizes ranging from

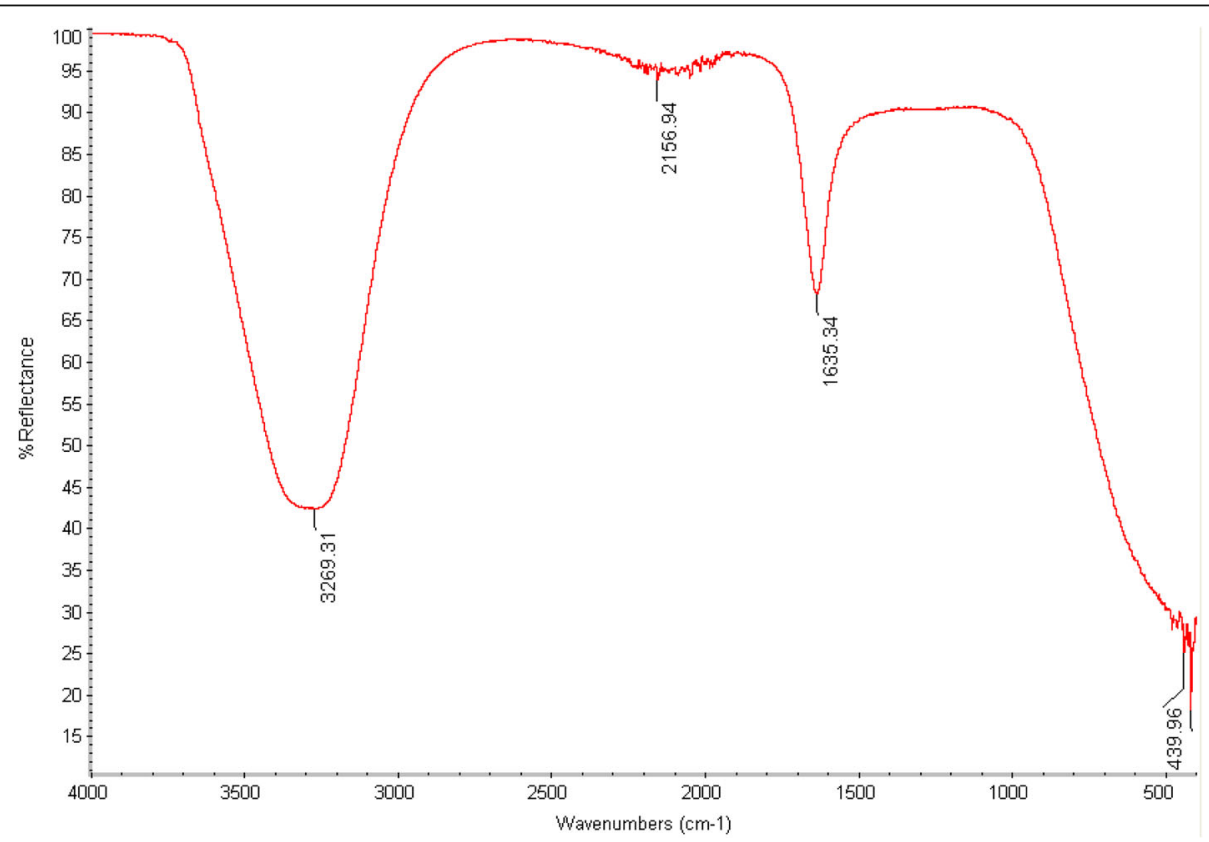

Fig. 5 Fourier transform infrared spectroscopy (FTIR) spectrum of AgNPs synthesized by reduction of $\mathrm{Ag}^{+}$ions by Trichoderma longibrachiatum 


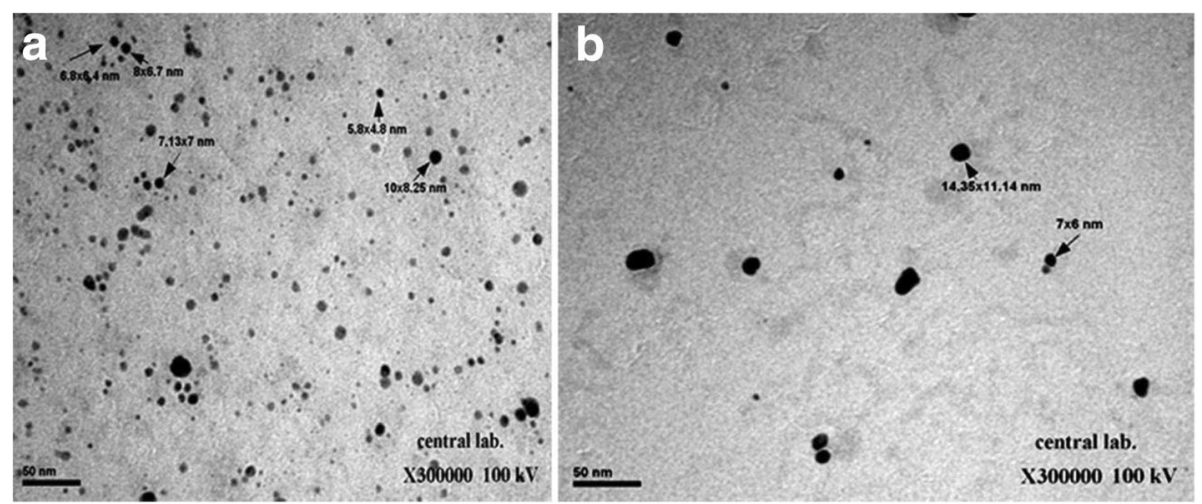

Fig. 6 TEM image of silver nanoparticles produced with Trichoderma longibrachtium after filtration of a $10 \mathrm{~g}$ fungal biomass and $\mathbf{b} 15 \mathrm{~g}$ fungal biomass

$\leq 1$ to $20 \mathrm{~nm}$ with $10 \mathrm{~g}$ fungal biomass. Fungal biomass of $15 \mathrm{~g}$ showed aggregation of silver nanoparticles. Monodispersed AgNPs with size $\geq 20 \mathrm{~nm}$ were observed after filtration. Two possible explanations of this observation could be proposed; first, the agglomeration might appear due to a possible accumulation of proteins and enzymes which were secreted during the biosynthesis, and second, the filtration might prevent the passing of different molecules of protein produced during the process of biosynthesis. The same type of the nanoparticles having variable shapes and sizes was observed in common biological systems in the range of 3-30 nm, when synthesized by $A$. niger (Jaidev and Narasimha 2010).

\section{Particle size analysis of AgNPs by dynamic light scattering (DLS) system}

The result of $10 \mathrm{~g}$ fungal biomass at $20 \%$ dilution without filtration, using DLS, showed good results. The data of DLS supported that the $Z$-average (r.nm) was 43.20. The average size of the synthesized AgNPs was $53.7 \mathrm{~nm}$ and $0.209 \mathrm{PdI}$ value. The obtained single peak indicated that the quality of the synthesized silver nanoparticles was good (Fig. 8a). In the case of $15 \mathrm{~g}$ fungal biomass, the results were not good with all dilutions (unshown data). One peak was obtained with a wide base, indicating that variable sizes of AgNPs were found in the solution. For the filtered AgNP solution produced from $10 \mathrm{~g}$ fungal biomass, the data of DLS supported that the $Z$-average (r.nm) is with $24.43 \mathrm{~nm}$ and $0.420 \mathrm{PdI}$ value (Fig. $8 \mathrm{~b}$ ). The average size of the synthesized AgNPs varied, and three peaks were observed at which with diameters of AgNPs were at 39.3, 4.4, and $1.5 \mathrm{~nm}$.

The result of $15 \mathrm{~g}$ fungal biomass after filtration and using DLS showed good results. The $Z$-average size was 29.15 and $0.412 \mathrm{PdI}$ value. Two peaks appeared showing AgNP diameters of 41.7 and $4.9 \mathrm{~nm}$ (Fig. 8c). Obtained results indicated that the value of the PdI, with $10 \mathrm{~g}$ fungal biomass, was 0.2 and 0.4 at dilution of 20 and $100 \%$, before and after filtration, respectively. Moreover, AgNPs biosynthesized by $T$. longibrachiatum were nearly monodispersed with the various sizes ranging from 5 to $30 \mathrm{~nm}$, in addition to the importance of filtration for removal of the aggregates. Obtained results from DLS
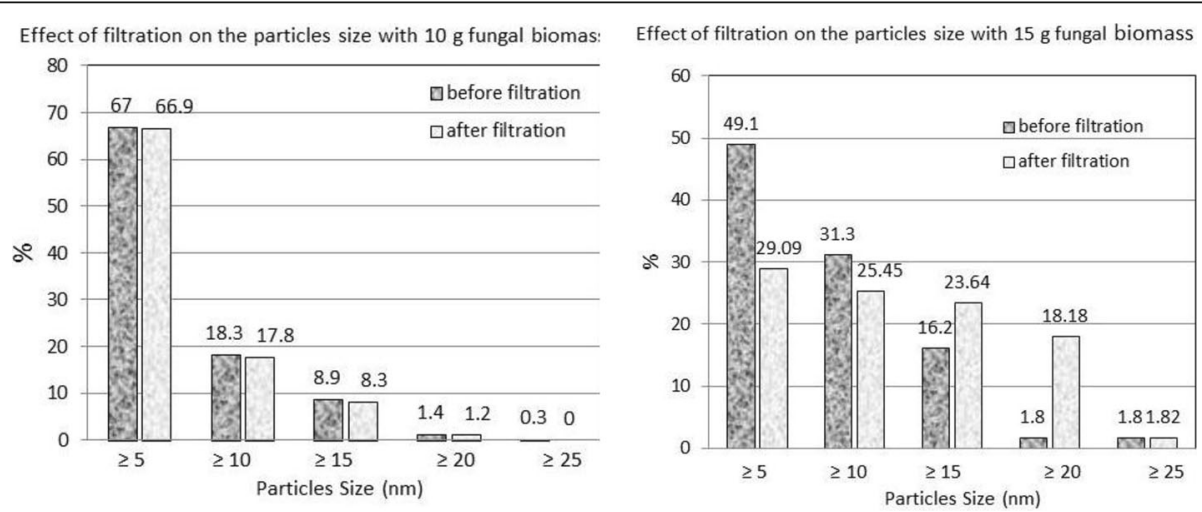

Fig. 7 Distribution of AgNP size from TEM analysis 

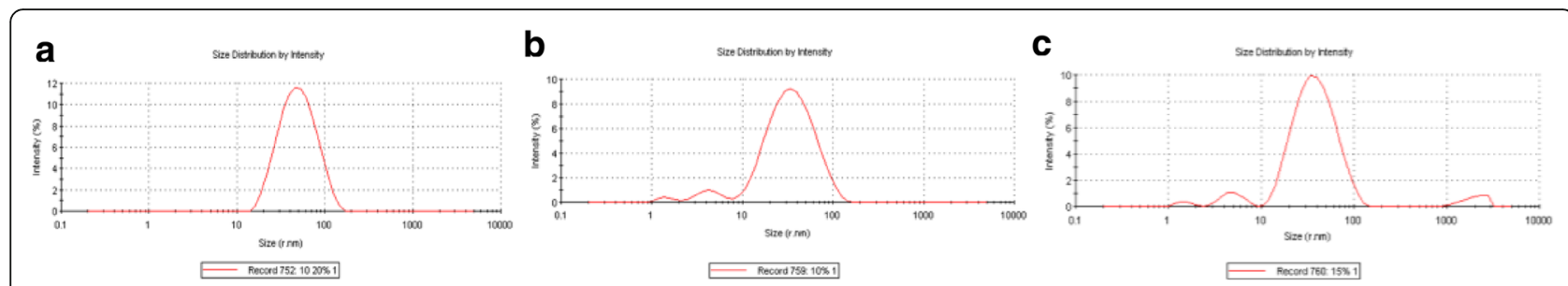

Fig. 8 Particle size distribution of AgNP solution synthesized by Trichoderma longibrachiatum for a $10 \mathrm{~g}$ fungal biomass at $20 \%$ dilution, b $10 \mathrm{~g}$ fungal biomass after filtration, and c $15 \mathrm{~g}$ fungal biomass after filtration

were in agreement with those obtained with TEM. The value of zeta potential of the silver nanoparticle solution produced from $10 \mathrm{~g}$ fungal biomass was $19.7 \mathrm{mV}$, with a single peak signifying the presence of repulsion among the synthesized nanoparticles (Fig. 9a). Meanwhile, with the silver nanoparticle solution produced from $15 \mathrm{~g}$ fungal biomass, the value of zeta potential was $-4.33 \mathrm{mV}$ (Fig. 9b). When all the particles in suspension have a large negative or positive zeta potential, they will tend to repel with each other and there will be no tendency of the particles to assemble together. However, if the particles have low zeta potential values, then there will be no force to prevent the particles from coming together and flocculating (Roy et al. 2013). The biosynthesized AgNPs were found to have negative zeta potential, which indicates the repulsion among the green synthesized silver nanoparticles and increases the stability of the formulation. It is evident that the AgNPs are polydispersed in nature, due to its high negative zeta potential; thus, the electrostatic repulsive force between them results in the prevention of agglomeration of the nanoparticles and is also very much helpful for long-term stability in the solution (Suresh et al. 2011 and Kotakadi et al. 2016).

\section{Stabilization of AgNP synthesis by $T$. longibrachiatum against agglomeration}

The stability of the synthesized particles was monitored for up to 60 days by using UV-vis spectral analysis, zeta potential. The UV-visible spectra of AgNPs showed an absorption peak at a wavelength of $414 \mathrm{~nm}$. Moreover, the $Z$-average size of AgNPs was $90.27 \mathrm{~nm}$

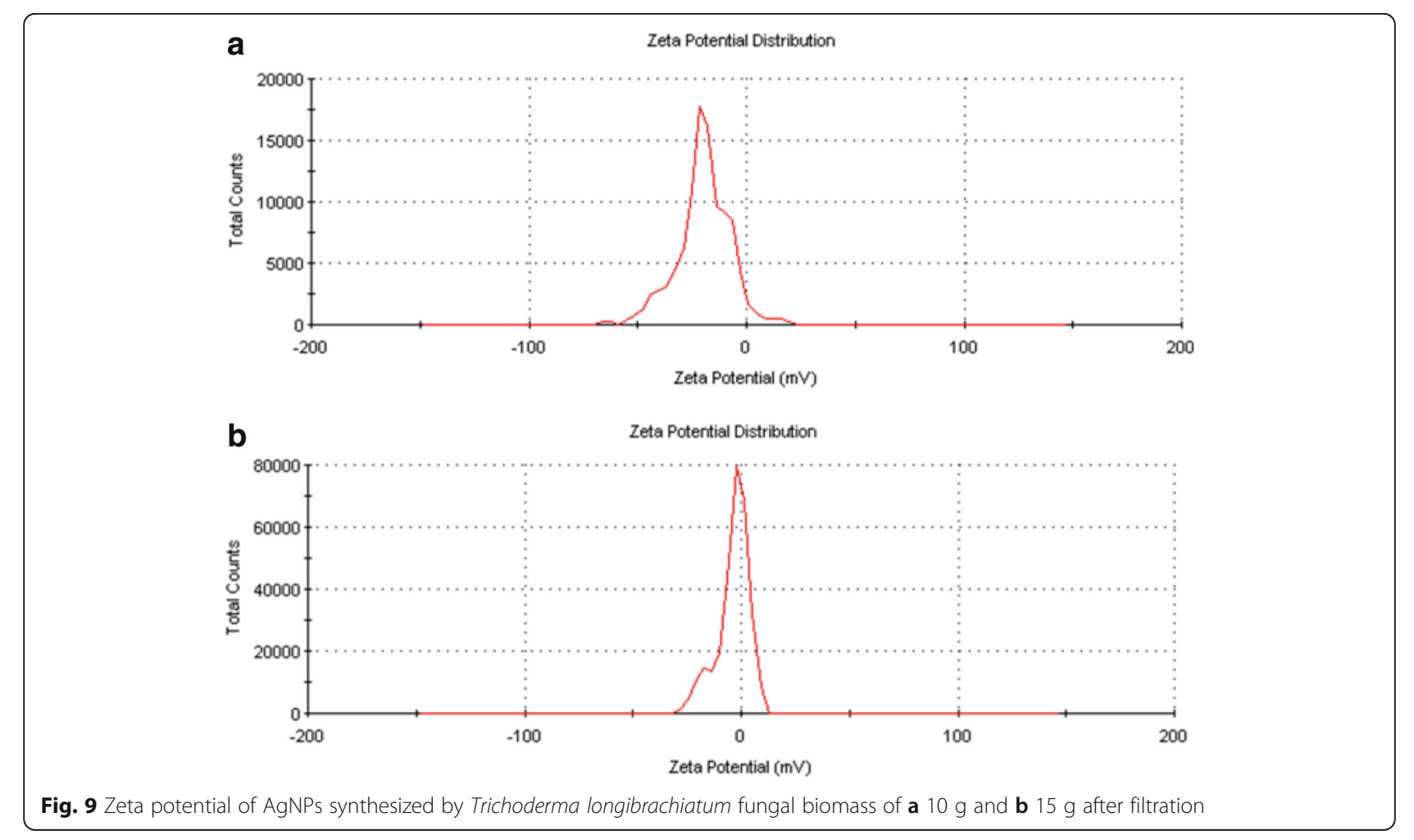


PdI value and $-0.8 \mathrm{mV}$ zeta potential. FTIR was used to confirm the stability of AgNPs, where it revealed two distinct peaks at 1635.34 and $3269.31 \mathrm{~cm}^{-1}$. Similar results were obtained as mentioned earlier (Fig. 8). The stability of nanoparticles in solution is very important with respect to antimicrobial activity as unstable AgNPs will not be able to disperse homogeneously, thus reducing the efficacy.

\section{Antifungal activity of biosynthesized AgNPs}

Determination of the antifungal activity of AgNPs synthesized by $T$. longibrachiatum was performed against nine fungal isolates: A. alternata, $F$. verticillioides, $F$. moniliforme, A. flavus, A. heteromorphus, P. glabrum, $P$. brevicompactum, $P$. grisea, and $H$. oryzae. The inhibition effect of AgNPs was analyzed in PDA by using colony formation units showed in Table 1 and Fig. 10 . In most studied fungi, high inhibition percentages of fungal colony formation were observed by comparing to the positive control of $1 \mathrm{mM} \mathrm{AgNO}$ or the negative control (water). In the present results, AgNPs were most effective against $P$. grisea, $F$. verticillioides, $H$. oryzae, F. moniliforme, and A. alternate with inhibition percentages of 98.9, 96.4, 95.1, 93.6, and 93.0\%, respectively. On other hand, the least efficiency of AgNPs was observed against F. oxysporum where it had $68.2 \%$ inhibition of colony formation. Statistical analysis showed that there were significant reductions $(P<0.05)$ in colony formation of the indicated fungal species resulting from the use of AgNPs and $\mathrm{AgNO}_{3}$ compared to the control (Table 1). Several studies revealed that biosynthesized AgNPs can be applied effectively in the control of microorganisms and the prevention of deleterious infections. The inhibitory effect of AgNPs on plant pathogenic fungus $P$. grisea was reported by Young et al. (2009) and Elamawi and El-shafey (2013). Biosynthesized AgNPs from $T$. longibrachiatum improved seed germination percentage and vigor index and reduced the disease incidence caused by $F$. oxysporium, a seed-borne pathogen on faba bean, tomato, and barley (Elamawi and Al-Harbi 2014). The AgNPs of smaller dimensions in this study were shown to be the most efficient against the tested phytopathogenic fungi. In fact, several studies have shown that AgNP activity is strongly dependent on the nanoparticle size (Rahimi et al. 2016).

Durán et al. (2005) attributed the antimicrobial activity of AgNPs to the formation of insoluble compounds by inactivation of sulfhydryl groups in the fungal cell wall and disruption of membrane-bound enzymes and lipids resulting in lysis of cell. It was also reported that the process may involve the binding of AgNPs to external proteins to create pores, interfering with DNA replication or forming reactive oxygen species (ROS) such as hydrogen peroxide, superoxide anions, and hydroxyl radicals (Jung et al. 2008; Duran et al. 2016; Ottoni et al. 2017).

\section{Conclusions}

In conclusions $T$. longibrachaitum was used in the biosynthesis of silver nanoparticles. Such type of synthesis may be considered as eco-friendly as it is free from any toxic chemicals or organic solvents during the biosynthesis process. Optimization of various parameters was carried out, using a "one at a time" strategy keeping all other variables constant and varying only one. Incubation at $28{ }^{\circ} \mathrm{C}$, fungal biomass at $10 \mathrm{~g}$, without agitation, and incubation for $72 \mathrm{~h}$ resulted in biosynthesis of AgNPs by T. longibrachaitum. Dilution at $20 \%$ and filtration, using Millipore filter paper $0.22 \mu \mathrm{m}$, were favorable for measuring the particle size distribution, using DLS system. T. longibrachiatum showed a potential for extracellular and stable biosynthesis of silver nanoparticles, as confirmed by UV-vis spectroscopy, which showed an absorption peak at $385 \mathrm{~nm}$. TEM revealed the formation of spherical nanoparticles with size ranging

Table 1 Inhibitory effect of synthesized AgNPs by Trichoderma longibrachiatum for different fungi

\begin{tabular}{|c|c|c|c|c|c|c|}
\hline \multirow[t]{2}{*}{ Fungal isolates } & \multicolumn{6}{|c|}{ Colony formation $/ \mathrm{cm}^{2}$} \\
\hline & Control & $\mathrm{AgNO}_{3}$ & $\mathrm{AgNO}_{3}$ efficiency (\%) & AgNPs & AgNP efficiency (\%) & $P$ value $<0.05$ \\
\hline A. alternata & 12.63 & 2.13 & 83.1 & 0.88 & 93.0 & 0.089 \\
\hline F. verticillioides & $29.67 c$ & $6.67 b$ & 77.5 & $1.08 \mathrm{a}$ & 96.4 & 0.002 \\
\hline F. moniliform & $17.63 c$ & $2.44 b$ & 91.8 & $1.13 a$ & 93.6 & 0.00 \\
\hline A. flavus & $25.63 c$ & $9.75 b$ & 62.0 & $3.42 \mathrm{a}$ & 86.7 & 0.00 \\
\hline A. heteromorphus & $10.17 c$ & $4.58 b$ & 55.0 & $1.67 a$ & 83.6 & 0.002 \\
\hline P. glabrum & $28.08 \mathrm{c}$ & $20.92 b$ & 25.5 & $6.83 a$ & 75.7 & 0.009 \\
\hline P. brevicompactum & $24.67 c$ & $13.50 \mathrm{~b}$ & 45.3 & $1.75 \mathrm{a}$ & 92.9 & 0.003 \\
\hline H. oryzae & $5.33 c$ & $1.98 b$ & 62.9 & $0.26 a$ & 95.1 & 0.00 \\
\hline P. grisea & $11.50 \mathrm{c}$ & $2.13 b$ & 81.5 & $0.13 a$ & 98.9 & 0.001 \\
\hline
\end{tabular}

Means followed by the same latter are not significantly different at the $0.05 \%$ level 


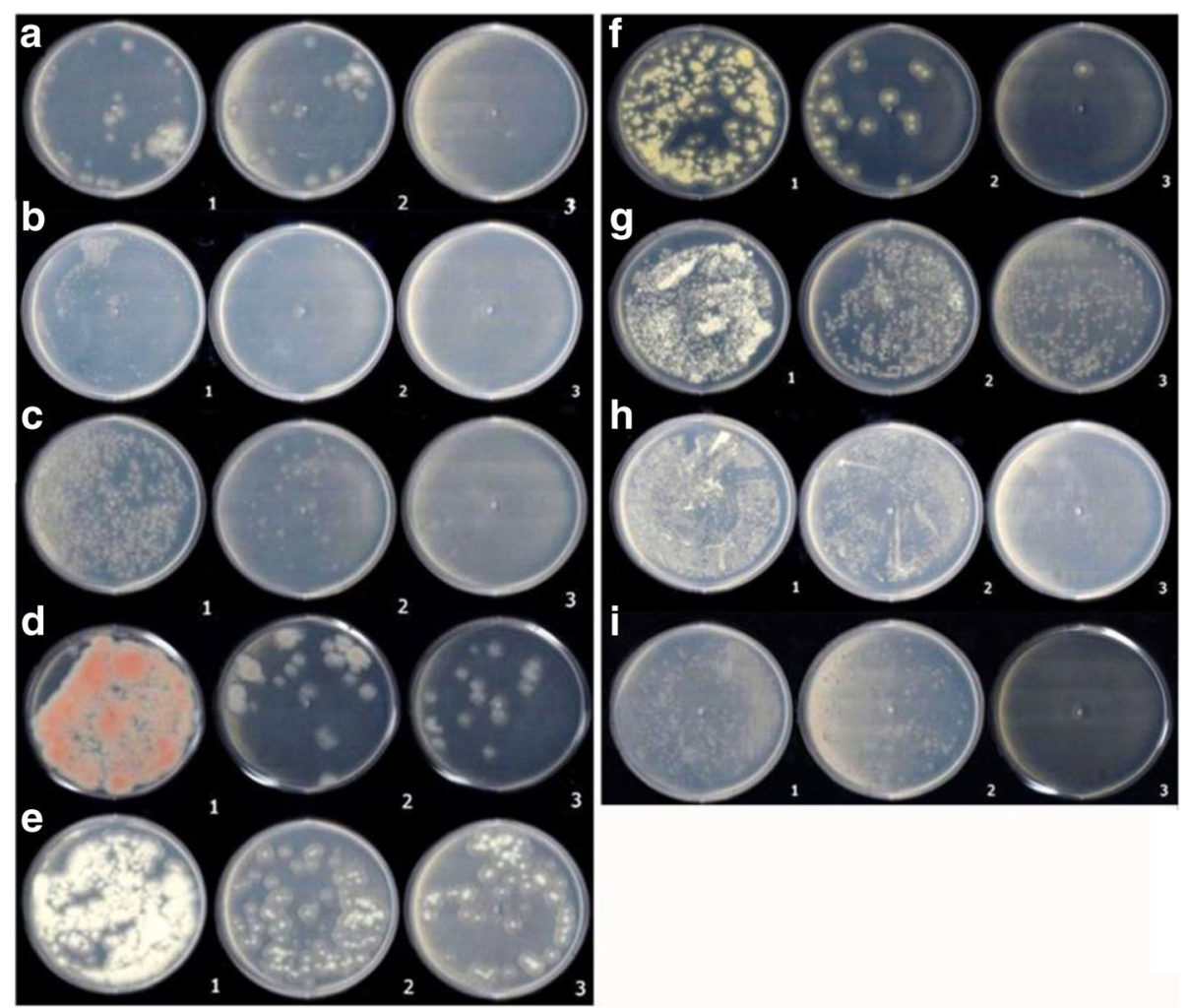

Fig. 10 Antifungal activity of different treatments, (1) control, (2) $\mathrm{AgNO}_{3}$, and (3) silver NPs, for different microorganisms: a Alternaria alternata, b Pyricularia grisea, c Fusarium verticillioides, d F. moniliform, e Aspergillus flavus, f A. heteromorphus, g Penicillium glabrum, h $P$. brevicompactum, and $\mathbf{i}$ Helminthosporium oryzae

between 5 and $25 \mathrm{~nm}$. FTIR showed the bands at 1634.92 and $3269.31 \mathrm{~cm}^{-1}$. DLS supported that the $Z$-average (r.nm) was $24.43 \mathrm{~nm}$ and $0.420 \mathrm{PdI}$ value. The zeta potential was $-19.7 \mathrm{mV}$ with a single peak.

Further studies are still needed to understand the precise molecular mechanism leading to the formation of AgNPs by biological methods in order to have a better control over the size and polydispersity of these nanoparticles. Further research should focus on the development of silver compounds and mixing with fungicides. At the same time, the environmental tracking of silver when applied in the field is important to assess its impact on environment and human health. This information is imperative for future registration and labeling of the AgNPs if they are to be used as fungicides for crop protection.

\section{Acknowledgements}

This research project was supported by a grant from the "Research Center for Female Scientific and Medical Colleges," Deanship of Scientific Research, King Saud University.

Authors' contributions

All authors read and approved the final manuscript.

\section{Competing interests}

The authors declare that they have no competing interests.

\section{Publisher's Note}

Springer Nature remains neutral with regard to jurisdictional claims in published maps and institutional affiliations.

\section{Author details}

${ }^{1}$ Rice Pathology Department, Plant Pathology Research Institute, Agricultural Research Center, PO Box 33717, Sakha, Kafr Elshiekh, Egypt. ${ }^{2}$ College of Science, King Saud University, PO Box 22452, Riyadh, Saudi Arabia. ${ }^{3}$ Physics Department, College of Science, King Saud University, PO Box 22452, Riyadh, Saudi Arabia.

Received: 27 September 2017 Accepted: 8 January 2018 Published online: 08 March 2018

\section{References}

Ahmad A, Mukherjee P, Senapati S, Mandal D, Khan Ml, Kumar R, Sastry M (2003) Extracellular biosynthesis of silver nanoparticles using the fungus Fusarium oxysporum. Colloids Surf B Biointerfaces 28:313-318

AshaRani PV, Mun GLK, Hande MP, Valiyaveettil S (2009) Cytotoxicity and genotoxicity of silver nanoparticles in human cells. ACS Nano 3(2):279-290

Balaji DS, Basavaraja S, Deshpande R, Mahesh DB, Prabhakar BK, Venkataraman A (2009) Extracellular biosynthesis of functionalized silver nanoparticles by strains of Cladosporium cladosporioides fungus. Colloids Surf B Biointerfaces 68(1):88-92

Barnett, H.L. and Hunter, B.B. 1995. Illustrated genera of imperfect fungi fourth edition

Capek I (2004) Preparation of metal nanoparticles in water-in-oil (w/o) microemulsions. Adv Colloid Interf Sci 110(1-2):49-74 
Das SK, Marsili E (2010) A green chemical approach for the synthesis of gold nanoparticles: characterization and mechanistic aspect. Rev Environ Sci Biotechnol 9:199-204

Durán N, Marcato PD, Alves OL, Souza G, Esposito E (2005) Mechanistic aspects of biosynthesis of silver nanoparticles by several Fusarium oxysporum strains. J Nanobiotechnol 3:1-8

Duran N, Nakazato G, Seabra AB (2016) Antimicrobial activity of biogenic silver nanoparticles, and silver chloride nanoparticles: an overview and comments. Appl Microbiol Biotechnol 100(15):6555-6570

Elamawi RM, Al-Harbi RE (2014) Effect of biosynthesized silver nanoparticles on Fusarium oxysporum fungus the cause of seed rot disease of faba bean, tomato and barley. J Plant Prot Path Mansoura Univ 1(12):991-1007

Elamawi RM, El-Shafey RA (2013) Inhibition effects of silver nanoparticles against rice blast disease caused by Magnapor thegrisea. Egypt J Agric Res 91(4):1271-1281

Emeka EE, Ojiefoh OC, Aleruchi C (2014) Evaluation of antibacterial activities of silver nanoparticles green-synthesized using pineapple leaf (Ananas comosus). Micron 57:1-5

Fayaz M, Balaji K, Girilal M, Yadav R, Kalaichelvan PT, Venketesan R (2010) Biogenic synthesis of silver nanoparticles and their synergistic effect with antibiotics: a study against grampositive and gram-negative bacteria. Nanomedicine 6:103-109

Fayaz M, Balaji K, Kalaichelvan PT, Venkatesan R (2009) Fungal based synthesis of silver nanoparticles - an effect of temperature on the size of particles. Colloids Surf. B. Biointerfaces 74:123-126

Gole AC, Dash V, Ramakrishnan SR, Sainkar AB, Mandale M, Sastry M (2001) Pepsin gold colloid conjugates, preparation, characterization, and enzymatic activity. Langmuir 17:1674

Harman AE (2006) Overview of mechanisms and uses of Trichoderma spp. Phytopathology 96(2):190-194

Harman GE, Howell CR, Viterbo A, Chet I, Lorito M (2004) Trichoderma species_opportunistic avirulent plant symbionts. Nat Rev Microbiol 2(1):43-56

Huang J, Zhan G, Zheng B, Sun D, Lu F, Lin Y, Chen H, Zheng Z, Zheng Y, Li Q (2011) Biogenic silver nanoparticles by Cacumen Platycladi extract: synthesis, formation mechanism and antibacterial activity. Ind Eng Chem Res 50:9095-9106

Ingle A, Gade A, Pierrat S, Sonnichsen C, Rai M (2008) Mycosynthesis of silver nanoparticles using the fungus Fusarium acuminatum and its activity against some human pathogenic bacteria. Curr Nanosci 4(2):141-144

Jaidev LR, Narasimha G (2010) Fungal mediated biosynthesis of silver nanoparticles, characterization and antimicrobial activity. Colloids Surf B $81: 430-433$

Jain N, Bhargava A, Majumdar S, Tarafdar JC, Panwar J (2011) Extracellular biosynthesis and characterization of silver nanoparticles using Aspergillus flavus NJP08: a mechanism perspective. Nano 3:635-641

Jeong SH, Yeo SY, Yi SC (2005) The effect of filler particle size on the antibacterial properties of compounded polymer/silver fibers. J Mater Sci 40(20):5407-5411

Jung WK, Koo HC, Kim KW, Shin S, Kim SH, Park YH (2008) Antibacterial activity and mechanism of action of the silver ion in Staphylococcus aureusand Escherichia coli. Appl Environ Microbiol 74(7):2171-2178

Kim YS, Kim JS, Cho HS, Rha DS, Kim JM, Park JD, Choi BS, Lim R, Chang HK, Chung YH, Kwon IH, Jeong J, Han BS, Yu IJ (2008) Twenty-eight day oral toxicity, genotoxicity, and gender-related issue distribution of silver nanoparticles in Sprague-Dawley rats. Inhal Toxicol 20:575-583

Kotakadi VS, Gaddam SA, Venkata SK, Sarma PVGK, Sai Gopal DVR (2016) Biofabrication and spectral characterization of silver nanoparticles and their cytotoxic studies on human CD34 +ve stem cells. Biotech 6(2):216

Mandal S, Phadtare S, Sastry M (2005) Interfacing biology with nanoparticles. Curr Appl Phys 5(2):118-127

Mukherjee P, Senapati S, Mandal D (2002) Extracellular synthesis of gold nanoparticles by the fungus Fusarium oxysporum. Chem Bio Chem 3(5):461-463

Murphy M, Ting K, Zhang X, Soo C, Zheng Z (2015) Current development of silver nanoparticle preparation, investigation, and application in the field of medicine. J Nanomater 2015:1-12

Nair AS, Pradeep T (2003) Halocarbon mineralization and catalytic destruction by metal nanoparticles. Curr Sci 84:1560-1564

Ottoni CA, Simaes MF, Fernandes S, Santos JG, da Silva ES, Souza RFB, Maiorano AE (2017) Screening of filamentous fungi for antimicrobial silver nanoparticles synthesis. AMB Expr 7:31-41
Pal S, Tak YK, Song JM (2007) Does the antibacterial activity of silver nanoparticles depend on the shape of the nanoparticle ? A study of the gram-negative bacterium Escherichia coli. Appl Environ Microbiol 73(6): 1712-1720

Rahimi G, Alizadeh F, Khodavandi A (2016) Mycosynthesis of silver nanoparticles from Candida albicans and its antibacterial activity against Escherichia coli and Staphylococcus aureus. Trop J Pharm Res 15(2):371-375

Rai M, Yadav A, Gade A (2009) Silver nanoparticles as a new generation of antimicrobials. Biotechnol Adv 27(1):76-83

Roy S, Mukherjee T, Chakraborty S, Kumar das T (2013) Biosynthesis, characterisation and antifungal activity of silver nanoparticles by the fungus Aspergillus foetidus MTCC8876. Digest J NanomaterBiostruct 8:197-205

Sastry M, Ahmad A, Islam NI, Kumar R (2003) Biosynthesis of metal nanoparticles using fungi and actinomycete. Curr Sci 85:162-170

Schultz S, Smith DR, Mock JJ, Schultz DA (2000) Single-target molecule detection with nonbleaching multicolor optical immunolabels. PNAS 97:996-1001

Sharma VK, Yngard RA, Lin Y (2009) Silver nanoparticles: green synthesis and their antimicrobial activities. Adv Colloid Interf Sci 145(1-2):83-96

Singh P, Balaji RB (2011) Biological synthesis and characterization of silver nanoparticles using the fungus Trichoderma harzianum. Asian J Exp Biol Sci 2:600-605

Sivasithamparam K, Ghisalberti EL (1998) Secondary metabolism in Trichoderma and Gliocladium. In: Kubicek CP, Harman GE (eds) Trichoderma and Gliocladium (1) basic biology, taxonomy and genetics. Taylor and Francis Ltd. London, pp 139-191

Solanki JN, Murthy ZVP (2010) Highly monodisperse and sub-nano silver particles synthesis via microemulsion technique. Colloids Surf A Physicochem Eng Asp 359:31-38

Solomon SD, Bahadory M, Jeyarajasingam AV, Rutkowsky SA, Boritz C (2007) Synthesis and study of silver nanoparticles. J Chem Educ 84:322-325

Sondi I, Salopek-Sondi B (2004) Silver nanoparticles as antimicrobial agent, a case study on E. coli as a model for Gram-negative bacteria. J Colloid Interface Sci 275:177-182

Suresh AK, Doktycz MJ, Wang W, Moon JW, Gu B, Meyer HM III, Hensley DK, Allison DP, Phelps TJ, Pelletier DA (2011) Monodispersed biocompatible silver sulfide nanoparticles: facile extracellular biosynthesis using the $\gamma$-proteobacterium Shewanella oneidensis. Acta Biomater 7:4253-4258

Vahabi K, Mansoori GA, Karimi S (2011) Biosynthesis of silver nanoparticles by fungus Trichoderma reesei (a route for large-scale production of AgNPs). Insciences J 1(1):65-79

Vandebriel RJ, Tonk ECM, de la Fonteyne-Blankestijn L, Gremmer ER, Verharen HW, van der Ven LT, van Loveren H, de Jong WH (2014) Immunotoxicity of silver nanoparticles in an intravenous 28-day repeated-dose toxicity study in rats. Part Fibre Toxicol 11(21):1-9

Wang Z, Chen J, Yang P, Yang W (2007) Biomimetic synthesis of gold nanoparticles and their aggregates using a polypeptide sequence. ApplOrganomet Chem 21(8):645-651

Young KJ, Byung HK, Geunhwa J (2009) Antifungal activity of silver ions and nanoparticles on phytopathogenic fungi. Plant Dis 93:1037-1043

\section{Submit your manuscript to a SpringerOpen ${ }^{\mathcal{O}}$ journal and benefit from:}

- Convenient online submission

- Rigorous peer review

- Open access: articles freely available online

- High visibility within the field

- Retaining the copyright to your article

Submit your next manuscript at $>$ springeropen.com 